\title{
Neuropsychological, psychiatric, and cerebral perfusion correlates of leukoaraiosis in Alzheimer's disease
}

S E Starkstein, L Sabe, S Vázquez, G Di Lorenzo, A Martínez, G Petracca, A Tesón, E Chemerinski, R Leiguarda

\begin{abstract}
Objective-To examine neurological, neuropsychological, psychiatric, and cerebral perfusion correlates of leukoaraiosis in Alzheimer's disease.

Methods-A consecutive series of patients with probable Alzheimer's disease was assessed with a comprehensive neuropsychological battery, a structured psychiatric evaluation, the unified Parkinson's disease rating scale, MRI, and single photon emission computed tomography with technetium 99m hexamethylpropyleneamine oxime (HMPAO) and regional cerebral perfusion measurements.

Results-Patients with Alzheimer's disease and leukoaraiosis were significantly more apathetic and had significantly more extrapyramidal signs than patients with Alzheimer's disease without leukoaraiosis. Patients with Alzheimer's disease with leukoaraiosis also had significantly lower bilateral perfusion in the basal ganglia, thalamus, and frontal lobes than patients with Alzheimer's disease without leukoaraiosis. On the other hand, there were no significant differences between groups in age, duration of illness, depression scores, severity of delusions, or deficits on specific neuropsychological tasks.

Conclusions-Leukoaraiosis in Alzheimer's disease may produce significant basal ganglia, and thalamic and frontal lobe dysfunction, which may be associated with more severe apathy and extrapyramidal signs.
\end{abstract}

(F Neurol Neurosurg Psychiatry 1997;63:66-73)

Keywords: Alzheimer's disease; leukoaraiosis; frontal lobes

Hachinski et $a l^{1}$ introduced the term leukoaraiosis to designate periventricular or subcortical areas of hypodensity on CT. This term was later used by other authors to refer to hyperintensities on the white matter or subcortical structures on T2 weighted MRI. ${ }^{2}$ Leukoaraiosis was reported to be present in $7.5 \%$ to $100 \%$ of patients with Alzheimer's disease, and this wide variability was explained by differences in case ascertainment, definitions of leukoaraiosis, and MRI methodology. ${ }^{3}$
Scheltens et $a l^{\beta}$ examined the prevalence and severity of leukoaraiosis in 29 patients with Alzheimer's disease and 24 age matched normal controls using MRI. They found that patients with Alzheimer's disease with senile onset had significantly more severe periventricular, white matter, and basal ganglia hyperintensities than normal controls. On the other hand, no significant differences were found between patients with Alzheimer's disease with presenile onset and normal controls. The authors suggested that the presence and location of leukoaraiosis may explain variations in clinical presentation (for example, language functions, extrapyramidal signs, and mood disturbances).

Fazekas et $a l^{4}$ studied 12 patients with Alzheimer's disease using T2 weighted MRI and found that $60 \%$ had white matter hyperintensities (not surrounding the ventricles). This prevalence was similar to that found in normal controls and was not related to hypertension or other vascular risk factors. On the other hand, the prevalence of periventricular hyperintensities (hyperintensities surrounding the lateral ventricles) was significantly higher in patients with Alzheimer's disease than in normal controls.

Marder et at examined CT and MRI of 158 patients with Alzheimer's disease for the presence of leukoaraiosis. Forty five per cent of the patients with Alzheimer's disease showed leukoaraiosis, but the authors could not find significant differences in severity of disease between patients with Alzheimer's disease with or without leukoaraiosis. They suggested that leukoaraiosis does not contribute to the cognitive impairment of Alzheimer's disease and should not preclude a diagnosis of Alzheimer's disease. However, the study had several limitations, such as the use of either CT or MRI (which have a different sensitivity to detect leukoaraiosis), the use of different CT and MRI scanners, the exclusion of patients with diffuse and symmetric hyperintensities, and the lack of comprehensive neuropsychological and psychiatric evaluations. By contrast, three other CT studies showed significant correlates of leukoaraiosis in Alzheimer's disease. Diaz et al $l^{6}$ showed that patients with Alzheimer's disease with leukoaraiosis had significantly more severe cognitive impairment than patients with Alzheimer's disease without leukoaraiosis, López et $a l^{7}$ reported that patients with Alzheimer's disease with leukoaraiosis had a higher risk for 
strokes than patients with Alzheimer's disease without leukoaraiosis, and Almkvist et $a l^{8}$ found that patients with Alzheimer's disease with leukoaraiosis had significantly more deficits on a tactile identification test than patients with Alzheimer's disease without leukoaraiosis. Thus an important unresolved issue is whether the presence of leukoaraiosis in Alzheimer's disease is significantly associated with specific cognitive, psychiatric, or other comorbid deficits.

There are few studies of cerebral perfusion correlates of leukoaraiosis in Alzheimer's disease. Using the xenon 133 method, Fazekas et $a l^{9}$ found more global brain hypoperfusion in demented patients with leukoaraiosis compared with patients with Alzheimer's disease without leukoaraiosis. Kawamura et $a l^{10}$ used xenon enhanced CT to examine 23 patients with ischaemic vascular dementia and 16 patients with Alzheimer's disease. They found a significant correlation between leukoaraiosis and reduced blood flow in subcortical grey matter in patients with ischaemic vascular dementia but not in patients with Alzheimer's disease. In a study using $\left[{ }^{99 \mathrm{~m}} \mathrm{TC}\right]-\mathrm{d}$, 1-hexamethylpropyleneamine oxime (HMPAO) SPECT, Waldemar et $a l^{11}$ found a significant correlation between the size of diffuse white matter hyperintensities and perfusion in the hippocampal region.

Studies of flow and metabolism with PET in patients with Alzheimer's disease and leukoaraiosis have also been performed. Herholz et $a l^{12}$ measured perfusion changes (using PET and $\left[{ }^{18} \mathrm{~F}\right]$ fluoromethane) in 20 patients with atherosclerotic carotid artery disease. They found significant perfusion reductions in patients with multiple large or confluent white matter hyperintensities. Finally, in a recent study that included 11 patients with vascular dementia assessed with ${ }^{18}$ fluorodeoxyglucose $\left({ }^{18} \mathrm{FDG}\right)$ PET, Sultzer et $a l^{13}$ found a significant association between the presence and severity of white matter hyperintensities and a global reduction of cortical metabolic activity. Whereas these few studies suggest an association between white matter hyperintensities and cortical and subcortical changes in flow and metabolism, studies of Alzheimer's disease with and without leukoaraiosis are lacking.

Because most studies show that about one third of patients with Alzheimer's disease have leukoaraiosis, an important question is whether this finding correlates with specific neurological, cognitive, psychiatric, and cerebral perfusion variables. To this end, we examined a consecutive series of 38 patients with Alzheimer's disease for the presence and correlates of leukoaraiosis. All patients had a comprehensive neuropsychological evaluation, a structured psychiatric interview, MRI, and ${ }^{99 m}$ Tc HMPAO SPECT studies. Based on MRI findings, patients were classified into those with or without leukoaraiosis.

\section{Patients and methods}

PATIENTS

A consecutive series of 46 patients examined for progressive cognitive decline at the Raúl
Carrea Institute of Neurological Research, who met the NINCDS-ADRDA criteria for probable Alzheimer's disease,${ }^{14}$ were included in the study. None of them had a history of stroke, one or more focal lesions on the MRI (T1 weighted), or a Hachinski ischaemic score ${ }^{15}>4$.

NEUROLOGICAL EXAMINATION

After informed consent, every patient was examined by a neurologist who was blind to the psychiatric, neuropsychological, MRI, and SPECT findings. The neurological examination consisted of the unified Parkinson's disease rating scale (UPDRS), ${ }^{16}$ which assesses the presence of extrapyramidal signs such as tremor, cogwheel rigidity, and akinesia (scores range from 0 to 4 , with 0 being normal).

\section{PSYCHIATRIC EXAMINATION}

Each patient was also examined by a psychiatrist blind to the other clinical and radiological findings using the following instruments:

\section{Structured clinical interview for DSM-III-R (SCID $)^{17}$}

The SCID is a semistructured diagnostic interview for making the major axis I DSM-IV diagnoses.

\section{Hamilton depression scale $(\text { Ham-d })^{18}$}

The HAM-D is a 17 item interviewer rated scale that measures psychological and autonomic symptoms of depression.

\section{Anosognosia questionnaire-dementia $(A Q-D)^{19}$}

This instrument consists of 30 questions divided into two sections. The first section assesses intellectual functioning, and the second examines changes in interests and personality. Form $\mathrm{A}$ is answered by the patient alone, whereas form B (a similar questionnaire written in the third person) is answered by the patient's care giver blind to the patient's answers in form A. The final score is the subtraction between scores in forms B and A. Thus positive scores indicate that the care giver rated the patient as more impaired than the patient's own rating.

\section{Dementia psychosis scale(DPS $)^{20}$}

This is an 18 item scale which quantifies the severity and types of delusions in demented patients at the time of the psychiatric evaluation.

\section{Pathological laughing and crying scale} $(\text { PLACS })^{21}$

This instrument is an interviewer rated scale that quantifies aspects of pathological affect, including the duration of the episodes, their relation to external events, degree of voluntary control, inappropriateness in relation to emotions, and degree of resultant distress.

Apathy scale 22

The apathy scale includes 14 items which are scored by the patient's relative or care giver. Each question has four possible answers, which are scored from 0 to 3 . Thus the apathy scale score ranges from 0 to 42 points, and higher 
scores indicate more severe apathy. We have shown the reliability and validity of the apathy scale in Alzheimer's disease. ${ }^{22}$

Irritability scale s2 $^{2}$

The irritability scale is a 14 item scale which is rated by the patient's relative or a care giver. Scores range from 0 to 42 , and higher scores indicate more severe irritability. We have shown the validity and reliability of this scale in Alzheimer's disease. ${ }^{22}$

NEUROPSYCHOLOGICAL EXAMINATION

The cognitive evaluation was carried out by a neuropsychologist who was blind to the neurological, psychiatric, and radiological data, and consisted of the following tests:

Mini mental state examination (MMSE) ${ }^{23}$

The MMSE is an 11 item examination reliable and valid in assessing a limited range of cognitive functions.

Raven's progressive matrices (RPM) ${ }^{24}$

The RPM assesses reasoning in the visual modality.

Wisconsin card sorting test ${ }^{25}$

This test measures the ability to develop new concepts and shift sets.

Controlled oral word association test ${ }^{26}$

This test examines access to semantic information with time constraint.

Digit $\operatorname{span}^{27}$

This test examines auditory attention.

Buschke selective reminding test ${ }^{28}$

This test measures verbal learning and memory during a multiple trial list learning task. The delayed trial was used as the outcome measure.

Benton visual retention test ${ }^{29}$

This test assesses visual perception and visual memory.

Token test $t^{30}$

This test examines verbal comprehension of sentences of increasing complexity.

Boston naming test ${ }^{31}$

This test examines the ability to name pictured objects.

Block design ${ }^{27}$

This test examines the presence of constructional apraxia.

Similarities $^{27}$

This test provides a measure of abstract reasoning.

SPECT EXAMINATION

After obtaining informed written consent a brain SPECT study using ${ }^{99 \mathrm{~m}}$ Tc-HMPAO (25 $\mathrm{mCi}$; Ceretec, Exametazime, Amersham International) was performed by previously published methods. The scan was acquired within one month of the clinical and MRI evaluations.
Patients sat with their eyes closed and ears unplugged in a quiet room with dim lights. Fifteen minutes after the injection patients were positioned within the scanner, parallel to the orbitomeatal line. The alignment was carried out with vertical and horizontal laser beams, and the head was held still by an ad hoc head holder. SPECT images were acquired with a General Electric $400 \mathrm{AC} / \mathrm{T}$ rotating gamma camera using a high resolution collimator and a $64 \times 64$ matrix. Sixty four images were obtained over $360^{\circ}$, with a 30 second acquisition time and a zoom of 1.6. Image reconstruction used a Butterworth filtering, a critical frequency of 0.44 , and a slice width of 1 pixel. Reconstructed brain slices were then reoriented in the orbitomeatal line using the sagittal and axial views, and a set of 30 axial, sagittal, and coronal sections at $6.4 \mathrm{~mm}$ increments were obtained. Final image resolution was 12 $\mathrm{mm}$ full width at half maximum in the plane of reconstructed transverse sections.

Square regions of interest (ROIs) consisting of $3 \times 3$ pixels $\left(\operatorname{voxel}(3 \times 3 \times 1\right.$ pixels $\left.)=2.35 \mathrm{~cm}^{3}\right)$ were used to obtain regional activity ratios in axial slices, with the cerebellum as reference. Specific ROIs were identified from the Matsui and Hirano atlas, ${ }^{32}$ and defined using each patient's MRI. Three measurements (anterior, medial, and posterior) were carried out for each of the following cortical areas: frontal inferior (orbital), frontal superior (dorsal), temporal inferior, temporal superior, and parietal. These areas were selected because they have previously been identified as showing the most significant perfusion changes in patients with Alzheimer's disease. ${ }^{33}$ These measurements were averaged for each cortical region on the right and left hemispheres. The ROIs were also placed in the basal ganglia, thalamus, and cerebellum. To determine the activity ratio (brain region/cerebellum), the counts in each ROI were divided by the average counts per ROI found in each cerebellar hemisphere. This ratio was used as a measure of relative perfusion. All SPECT measurements were performed by a neuroradiologist blind to the clinical data. The between and within rater reliabilities of these measurements have been previously reported. ${ }^{34}$ This study was approved by the ethical review committee of the Raúl Carrea Institute of Neurological Research.

MRI EXAMINATION

Magnetic resonance imaging was carried out using a General Electric MR Max 0.5 Tesla device (General Electric, Wisconsin). All sequences were taken with a spin echo technique, and $5 \mathrm{~mm}$ thick slices (no gap) were obtained in the axial and coronal ( $\mathrm{T} 1$ sequences ( $\mathrm{TR}=640, \mathrm{TE}=25,4 \mathrm{NEX}, \mathrm{FOV}=22$, matrix $=160 \times 192$ ), and sagittal planes (T2 sequences $(\mathrm{TR}=4000, \mathrm{TE}=45-90), 1 \mathrm{NEX}$, FOV $=22$, matrix $=160 \times 192$ ).

Two neuroradiologists (GDL and AM) who were blind to the clinical and SPECT findings assessed the presence and extension of caps, bands, and white matter, basal ganglia, and infratentorial hyperintensities, which were quantified using the method of Scheltens et a ${ }^{35}$ 
Caps were defined as areas of higher signal intensities at the level of the occipital and frontal horns, and bands were defined as signal hyperintensities surrounding the body of the lateral ventricles. Scores were 0 (absence of caps or bands), 1 (caps or bands $<5 \mathrm{~mm}$ ), and 2 (caps or bands $>6 \mathrm{~mm}$ and $<10 \mathrm{~mm}$ ). White matter hyperintensities were defined as signal hyperintensities at the level of the frontal, temporal dorsal, parietal, occipital dorsal, and temporo-occipital regions, and were scored as 0 (absent), 1 ( $<3 \mathrm{~mm}, \mathrm{n}<5), 2(<3 \mathrm{~mm}, \mathrm{n}>6)$, 3 (4-10 mm, $\mathrm{n}<5), 4(4-10 \mathrm{~mm}, \mathrm{n}>6), 5(>11$ $\mathrm{mm}, \mathrm{n}>1$ ), and 6 (confluent). Basal ganglia and internal capsule hyperintensities were defined as signal hyperintensities at the level of the head of the caudate, putamen, globus pallidus, thalamus, internal capsule, and external capsule (scores were similar to white matter hyperintensities). Infratentorial hyperintensities were rated as signal hyperintensities at the level of the cerebellar hemispheres, vermis, pons, and medulla (scores were similar to white matter hyperintensities). The between rater reliability for the above measures was high ( $\kappa$ values ranged from 0.71 to 0.92 ). Based on the findings of Scheltens et $a l^{35}$ patients with Alzheimer's disease with white matter hyperintensities $>4$ on at least one region of both left and right hemispheres, or scores $>4$ in at least two regions within a single hemisphere were included in the leukoaraiosis group. To examine groups with or without clearcut leukoaraiosis, patients with Alzheimer's disease with white matter hyperintensities $<2$ in each brain area examined were included in the no leukoaraiosis group whereas patients with white matter hyperintensities scores of 3 in 1 or more brain areas or $>4$ in a single brain area were excluded from the study. Scores for caps, bands, basal ganglia, and infratentorial hyperintensities were not used for group classification.

\section{STATISTICAL ANALYSIS}

Statistical analysis was carried out with univariate and multivariate analysis of variance (ANOVA and MANOVA), and Pearson's correlations. Whether the data fitted a normal distribution was analysed with a KolmogorovSmirnov test, and data without a normal distribution were analysed by Mann-Whitney $U$ test. Frequency distributions were calculated using $\chi^{2}$ tests with a Yates correction for expected cell sizes $<5$ and Fisher's exact tests. All $\mathrm{P}$ values are two tailed.

\section{Results}

DEMOGRAPHIC FINDINGS (TABLE 1)

Based on our diagnostic scheme, 15 patients were included in the Alzheimer's disease withleukoaraiosis group and 23 patients were included in the Alzheimer's disease without leukoaraiosis group. The remaining eight patients either did not meet the MRI criteria $(n=3$; see MRI EXAMINATION) or had missing clinical data (two patients had no UPDRS scores and three patients had incomplete psychiatric or neuropsychological evaluations) prompting their exclusion. No significant differences were found in age, sex, years of
Table 1 Demographic data

\begin{tabular}{lcc}
\hline & AD without & \\
& LA & AD with LA \\
\hline Patients (n) & 23 & 15 \\
Age (mean (SD) y) & $70.3(6.8)$ & $73.9(5.4)$ \\
Sex (\%F) & 70 & 73 \\
Education (mean (SD) y) & $10.9(5.0)$ & $10.2(5.9)$ \\
Duration of illness (mean (SD) y) & $2.9(1.5)$ & $2.6(2.1)$ \\
\hline
\end{tabular}

$\mathrm{AD}=$ Alzheimer's disease; $\mathrm{LA}=$ leukoaraiosis.

Table 2 Neurological findings (mean (SD))

\begin{tabular}{lll}
\hline & AD without LA & AD with LA \\
\hline Resting tremor & $0.05(0.2)$ & $0.45(0.8)$ \\
Action tremor & $0.05(0.2)$ & $0.36(0.6)$ \\
Rigidity & $0.11(0.3)$ & $1.10(0.9)$ \\
Finger tapping & $0.23(0.5)$ & $0.90(0.8)$ \\
Hand movements & $0.23(0.5)$ & $1.00(0.8)$ \\
Alternating movements & $0.24(0.5)$ & $1.01(0.8)$ \\
Leg agility $^{\star}$ & $0.23(0.5)$ & $1.18(0.9)$ \\
Posture $_{\text {Gait disturbances }}^{\star}$ & $0.23(0.4)$ & $0.90(0.5)$ \\
Postural stability & $0.25(0.4)$ & $0.81(0.6)$ \\
Body bradykinesia & $0.52(0.9)$ & $0.45(0.6)$ \\
\hline
\end{tabular}

$\star \mathrm{P}<0.05$.

$\mathrm{AD}=$ Alzheimer's disease; $\mathrm{LA}=$ leukoaraiosis.

education, and duration of illness between patients with Alzheimer's disease with or without leukoaraiosis. All patients had memory problems at the onset of the illness, and their dementia profile was typical of Alzheimer's disease (relatively more severe deficits on tests of anterograde memory and language) (table $4)$.

NEUROLOGICAL FINDINGS (TABLE 2)

A MANOVA for UPDRS scores showed a significant main effect (Wilks' $\lambda=0.33, \mathrm{df}=10,20$, $\mathrm{P}<0.01$ ) (patients with Alzheimer's disease with leukoaraiosis showed significantly more severe overall extrapyramidal signs than patients with Alzheimer's disease without leukoaraiosis). Post hoc comparisons (Mann-Whitney $U$ tests) showed that patients with Alzheimer's disease with leukoaraiosis had significantly more severe rigidity $(\mathrm{P}<0.01)$, deficits in hand movements $(\mathrm{P}<0.01)$, alternating movements $(\mathrm{P}<0.01)$, leg agility $(\mathrm{P}<0.01)$, posture $(P<0.001)$, and gait disturbances $(P<0.01)$ than patients with Alzheimer's disease without leukoaraiosis.

Hypertension was found in one patient without leukoaraiosis $(4 \%)$ and five patients with leukoaraiosis (33\%) (Fisher's exact test $\mathrm{P}<0.05)$. None of the patients had diabetes or a history of ischaemic heart disease.

PSYCHIATRIC FINDINGS (TABLE 3)

Patients with Alzheimer's disease and leukoaraiosis had significantly higher apathy scores than patients with Alzheimer's disease without leukoaraiosis $(t=2.1, \mathrm{df}=36, \mathrm{P}<0.05)$. No significant between group differences were found on the remaining psychiatric variables.

NEUROPSYCHOLOGICAL FINDINGS (TABLE 4) A MANOVA showed no significant difference on cognitive tasks between patients with Alzheimer's disease with or without leukoaraiosis (Wilks' $\lambda=0.64, \mathrm{df}=11,26, \mathrm{NS}$ ). 
Table 3 Psychiatric findings (mean (SD))

\begin{tabular}{lcc}
\hline & $\begin{array}{c}\text { AD without } \\
\text { LA group }\end{array}$ & $\begin{array}{l}\text { AD with } \\
\text { LA group }\end{array}$ \\
\hline Psychosis dementia scale & $1.6(2.7)$ & $1.5(5.4)$ \\
Hamilton depression scale & $10.2(8.0)$ & $13.7(10.1)$ \\
Anosognosia questionnaire-dementia & $7.1(13.3)$ & $7.4(19.7)$ \\
Irritability scale & $10.9(7.5)$ & $15.6(11.2)$ \\
Apathy scale & $19.2(8.7)$ & $26.0(9.8)$ \\
Pathological laughing and crying scale & $5.0(5.3)$ & $7.9(6.2)$ \\
Major depression (\% patients) & 13 & 20 \\
Dysthymia (\% patients) & 39 & 47 \\
No depression (\% patients) & 48 & 33 \\
\hline
\end{tabular}

$\mathrm{AD}=$ Alzheimer's disease; $\mathrm{LA}=$ leukoaraiosis. ${ }^{\star} \mathrm{P}<0.05$.

Table 4 Neuropsychological findings (mean (SD))

\begin{tabular}{lcc}
\hline & $\begin{array}{c}\text { AD without } \\
\text { LA group }\end{array}$ & $\begin{array}{l}\text { AD with } \\
\text { LA group }\end{array}$ \\
\hline Mini-mental state exam (mean score) & $20.4(5.4)$ & $20.5(4.7)$ \\
Buschke selective reminding test delayed & $2.1(2.2)$ & $3.1(2.6)$ \\
Benton visual retention test & $5.7(2.2)$ & $4.9(1.3)$ \\
Token test & $18.6(4.6)$ & $18.2(4.9)$ \\
Boston naming test & $14.5(3.9)$ & $12.7(4.4)$ \\
Wisconsin card sorting test: & $2.6(2.3)$ & $1.2(1.4)$ \\
$\quad$ Categories & $32.2(20.2)$ & $45.5(13.0)$ \\
$\quad$ Errors & $23.8(21.6)$ & $29.8(19.5)$ \\
Perseverations & $29.7(10.0)$ & $27.0(9.3)$ \\
Oral word controlled association test & $37.6(33.0)$ & $20.0(26.9)$ \\
Raven's progressive matrices (percentile) & $5.2(1.0)$ & $4.3(1.8)$ \\
Digits forward & $3.0(1.3)$ & $2.3(1.6)$ \\
Digits backward & $3.2(2.4)$ & $2.0(2.0)$ \\
Block design & $10.9(6.9)$ & $7.0(6.7)$ \\
Similarities & & \\
\hline
\end{tabular}

$\mathrm{AD}=$ Alzheimer's disease; $\mathrm{LA}=$ leukoaraiosis.

Table 5 SPECT findings (mean (SD))

\begin{tabular}{lll}
\hline & $\begin{array}{l}\text { AD without } L A \\
\text { group }\end{array}$ & $\begin{array}{l}\text { AD with } L A \\
\text { group }\end{array}$ \\
\hline Frontal inferior & $74.7(10.1)$ & $70.3(11.3)$ \\
Frontal superior & $80.0(10.2)$ & $72.5(9.1)$ \\
Temporal inferior & $77.5(8.4)$ & $79.0(6.2)$ \\
Temporal superior & $78.7(9.5)$ & $80.1(6.3)$ \\
Parietal & $77.9(9.8)$ & $78.6(6.9)$ \\
Basal ganglia & $85.7(8.1)$ & $80.3(6.3)$ \\
Thalamus & $79.7(7.2)$ & $75.0(5.17)$ \\
\hline
\end{tabular}

$\mathrm{AD}=$ Alzheimer's disease; $\mathrm{LA}=$ leukoaraiosis. ${ }^{\star} \mathrm{P}<0.05$. Numbers are proportional measures relative to the cerebellum $\times 100$.

SPECT FINDINGS (TABLE 5)

A three way ANOVA with repeated measures (group $\times$ region $\times$ side) showed no significant group effect $(F(1,36)=1.09$, NS), no significant group $\times$ side interaction $(F(1,36)=0.26$, NS), but a significant group $\times$ region interaction $(F(6,216)=4.04, \quad \mathrm{P}<0.001)$. Posthoc analyses showed that patients with Alzheimer's disease with leukoaraiosis had significantly lower bilateral perfusion in the basal ganglia $(\mathrm{P}<0.05)$, thalamus $(\mathrm{P}<0.01)$, and both inferior $(\mathrm{P}<0.01)$ and superior frontal regions $(\mathrm{P}<0.0001)$. No significant between group differences were found on the remaining brain areas.

MRI FINDINGS (TABLE 6)

As expected, MANOVA for leukoaraiosis showed a significant overall effect (Wilk's $\lambda=0.27, \mathrm{df}=5,32, \mathrm{P}<0.0001)$. On individual comparisons (Mann-Whitney $U$ tests) patients with Alzheimer's disease with leukoaraiosis showed significantly more severe caps $(\mathrm{P}<0.001)$, bands $(\mathrm{P}<0.001)$, white matter hyperintensities $(\mathrm{P}<0.0001)$, and basal ganglia hyperintensities $(\mathrm{P}<0.001)$.
Table 6 MRI findings (mean (SD))

\begin{tabular}{llc}
\hline & $\begin{array}{l}\text { AD without } \\
\text { LA group }\end{array}$ & $\begin{array}{l}\text { AD with } \\
\text { LA group }\end{array}$ \\
\hline Caps * & $3.3(1.4)$ & $5.5(1.3)$ \\
Bands * & $1.2(0.6)$ & $2.4(0.7)$ \\
$\begin{array}{l}\text { White matter hyperintensities } \\
\quad \text { WMH) (total) }\end{array}$ & $1.9(1.8)$ & $20.2(10.2)$ \\
Temporal WMH * & & \\
Frontal WMH * & $0.1(0.2)$ & $2.3(1.6)$ \\
Parietal WMH * & $0.3(0.5)$ & $5.3(1.9)$ \\
Occipital WMH * & $0.5(1.2)$ & $8.0(2.1)$ \\
Thalamic hyperintensities & $1.0(1.5)$ & $4.6(2.4)$ \\
Basal ganglia hyperintensities * & 0 & $0.8(1.0)$ \\
Infratentorial hyperintensities * & 0 & $6.3(7.5)$ \\
\hline
\end{tabular}

$\mathrm{AD}=$ Alzheimer's disease; $\mathrm{LA}=$ leukoaraiosis. ${ }^{\star} \mathrm{P}<0.05$.

\section{CORRELATIONS BETWEEN SPECT AND MRI} FINDINGS

A correlation matrix analysis between caps, bands, white matter, basal ganglia, and infratentorial hyperintensities, and perfusion in frontal, temporal, parietal, basal ganglia, and thalamic regions was calculated. Using a conservative level of $\mathrm{P}<0.01$, there were significant negative correlations (more severe leukoaraiosis and lower cerebral perfusion) between frontal perfusion and both basal ganglia $(r=-0.41)$ and infratentorial hyperintensities $(r=-0.43)$, as well as between basal ganglia perfusion and both basal ganglia $(r=-0.38)$ and white matter hyperintensities $(r=-0.38)$.

LEUKOARAIOSIS WITH AND WITHOUT BASAL GANGLIA HYPERINTENSITIES

To examine whether basal ganglia hyperintensities have specific neurological and neuropsychological correlates, patients with leukoaraiosis were divided into those with $(n=9)$ or without $(n=6)$ basal ganglia hyperintensities. Patients with basal ganglia hyperintensities showed significantly more severe apathy $(F(2$, $35)=3.03, P<0.05)$, rigidity $(P<0.001)$, deficits on hand movements $(\mathrm{P}<0.01)$, deficits on alternating movements $(\mathrm{P}<0.01)$, deficits with leg agility $(\mathrm{P}<0.01)$, postural problems $(\mathrm{P}<0.01)$, gait problems $(\mathrm{P}<0.05)$, deficits on auditory attention $(F(2,35)=5.16, \mathrm{P}<0.01)$, and significantly more severe caps $(F(2$, $35)=11.6, \mathrm{P}<0.0001)$, bands $(F(2,35)=28.1$, $\mathrm{P}<0.0001)$, and white matter hyperintensities $(F(2,35)=28.1, \mathrm{P}<0.0001)$ than patients with either leukoaraiosis but no basal ganglia hyperintensities or patients without leukoaraiosis (table 7).

\section{Discussion}

This study examined neurological, cognitive, psychiatric, and cerebral perfusion correlates of leukoaraiosis in Alzheimer's disease and there were several important findings. Patients with Alzheimer's disease with leukoaraiosis had significantly more severe apathy and extrapyramidal signs than patients with Alzheimer's disease without leukoaraiosis. Patients with Alzheimer's disease with leukoaraiosis also had significantly more severe bilateral hypoperfusion in the basal ganglia, thalamus, and frontal lobes than patients with Alzheimer's disease without leukoaraiosis. On the other hand, there were no significant differences between patients with 
Table 7 Leukoaraiosis with and without basal ganglia hyperintensities (mean (SD))

\begin{tabular}{|c|c|c|c|}
\hline & $\begin{array}{l}\text { AD without } \\
L A\end{array}$ & $\begin{array}{l}A D \text { with } L A \\
\text { (no } B G H)\end{array}$ & $\begin{array}{l}A D \text { with } \\
L A \text {, with } \\
B G H\end{array}$ \\
\hline Patients (n) & 23 & 6 & 9 \\
\hline Apathy scale * & $19.2(8.7)$ & $23.3(13.4)$ & $28.3(5.2)$ \\
\hline Rigidity * & $0.1(0.3)$ & $0.5(1.0)$ & $1.2(0.8)$ \\
\hline Hand movements * & $0.2(0.5)$ & $0.5(0.5)$ & $1.2(0.8)$ \\
\hline $\begin{array}{l}\text { Alternating } \\
\text { movements } \star\end{array}$ & $0.2(0.5)$ & $0.5(0.5)$ & $1.2(0.9)$ \\
\hline Leg agility $\star$ & $0.2(0.5)$ & $0.7(0.9)$ & $1.3(0.9)$ \\
\hline Posture $\star$ & $0.2(0.4)$ & $0.7(0.5)$ & $1.0(0.5)$ \\
\hline Gait disturbances * & $0.2(0.4)$ & $0.7(0.5)$ & $0.7(0.7)$ \\
\hline Digits forward $\star$ & $5.2(0.9)$ & $5.4(1.1)$ & $3.7(1.7)$ \\
\hline Caps ^ & $3.3(1.4)$ & $4.6(1.0)$ & $6.1(1.5)$ \\
\hline Bands * & $1.2(0.6)$ & $2.3(0.8)$ & $2.4(0.8)$ \\
\hline \multicolumn{4}{|l|}{ White matter } \\
\hline hyperintensities * & $1.9(1.8)$ & $6.1(0.5)$ & $14.6(1.1)$ \\
\hline
\end{tabular}

Alzheimer's disease with or without leukoaraiosis on neuropsychological tests or other psychiatric disorders such as depression and emotional lability. Finally, there were significant correlations between both basal ganglia and infratentorial hyperintensities and reduced frontal perfusion, as well as between white matter and basal ganglia hyperintensities and reduced basal ganglia perfusion.

Before further comments, some limitations of our study should be pointed out. Firstly, our sample of Alzheimer's disease with leukoaraiosis only included 15 patients, and future studies should include a larger series. However, all our patients with Alzheimer's disease with leukoaraiosis had severe white matter, or basal ganglia hyperintensities, or both, all of them were examined with a comprehensive clinical evaluation and SPECT, and none of them had a history of strokes or ischaemic lesions on the MRI. Furthermore, a recent study showed that white matter hyperintensities in Alzheimer's disease consist of a loss of myelinated axons, which may represent some form of accelerated aging. ${ }^{2}$ The second limitation was that our patients with Alzheimer's disease with leukoaraiosis had severe and widespread hyperintensities, and correlations between specific cognitive deficits and focal brain hyperintensities could not be examined. Thus it is possible that significant correlations with specific cognitive tasks may be shown in patients with more focal leukoaraiosis.

The first important finding of our study was that patients with Alzheimer's disease with leukoaraiosis had significantly more severe apathy and extrapyramidal signs than patients with Alzheimer's disease without leukoaraiosis. Apathy was defined as the "absence or lack of feeling, emotions, interest, or concern" 36 and has usually been associated with frontal lobe dysfunction. Stuss and Benson ${ }^{37}$ described the "pseudodepressive" syndrome (featuring apathy, lack of concern, absence of drive, and poor emotional reactivity) as a frequent psychiatric sequel of patients with frontal dorsolateral lesions. In a related study of apathy in patients with acute strokes, we found apathy to be significantly more frequent among patients with lesions of the lenticular or posterior limb of the internal capsule. ${ }^{38}$ Thus apathy in Alzheimer's disease may be related to either relatively more severe frontal dysfunction (as shown by SPECT) or relatively more severe leukoaraiosis in the region of the posterior limb of the internal capsule, which may damage relevant pallidomesencephalic and pallidonigral projections.

In a more recent study we found that $23 \%$ of a consecutive series of 103 patients with Alzheimer's disease had parkinsonism, whereas $56 \%$ had isolated extrapyramidal signs. ${ }^{39} \mathrm{We}$ also reported relatively more severe left frontal hypoperfusion in patients with Alzheimer's disease with extrapyramidal signs compared with patients with Alzheimer's disease without such signs. ${ }^{40}$ Findings in the present study suggest that leukoaraiosis may play an important part in the mechanism of extrapyramidalism in Alzheimer's disease. The higher prevalence of these symptoms in the Alzheimer's disease with leukoaraiosis group may be related to both the higher prevalence of white matter and basal ganglia hyperintensities, and the lower basal ganglia perfusion found in the Alzheimer's disease with leukoaraiosis group compared with the Alzheimer's disease group without leukoaraiosis. Among patients with an akinetic rigid syndrome due to multisystem atrophy or progressive supranuclear palsy, SPECT and PET studies showed similar perfusion deficits involving the basal ganglia and the frontal lobes. ${ }^{41} 42$ Moreover, the akinetic-rigid syndrome in these disorders does not improve with dopaminergic agonists, and we have recently shown that the extrapyramidal signs in Alzheimer's disease do not improve after the subcutaneous injection of apomorphine. ${ }^{39}$

In a related study of 11 patients with vascular dementia, Sultzer et $a l^{13}$ found a significant correlation between cortical metabolic activity and the severity of total ipsilateral subcortical white matter lesions (as shown with 0.35 Tesla MRI). More specifically, they found a one third reduction of global cortical metabolism in patients with moderate to severe anterior periventricular hyperintensities compared with patients without such lesions, as well as a significant correlation between total white matter hyperintensities and hypometabolism in the temporal cortex. One limitation of the study was that eight of the 11 patients also had single or multiple subcortical stroke lesions, and whether cortical metabolic changes were related to these lesions or to the changes in white matter could not be determined.

Our study comprised 15 patients with moderate to severe white matter and basal ganglia hyperintensities but no subcortical stroke lesions on the MRI, a negative history of strokes, and a Hachinski ischaemic score $<4$. Thus we were able to examine cortical metabolic changes produced by brain hyperintensities without the confounding influence of subcortical stroke lesions. None the less, we replicated the finding of Sultzer et $a l^{13}$ of significant cortical metabolic changes in demented patients with moderate to severe white matter and basal ganglia hyperintensities, as patients with Alzheimer's disease with leukoaraiosis had significantly more severe bilateral frontal hypoperfusion than patients with Alzheimer's disease without leukoaraiosis. 
The second major finding of the study was a significant correlation between the severity of basal ganglia and infratentorial hyperintensities and frontal lobe perfusion. This finding may be explained by neuronal cortical deactivation produced by disruption of subcorticocortical circuits. The present study also showed a significant correlation between the severity of white matter and basal ganglia hyperintensities and basal ganglia hypoperfusion. On the other hand, it has not been shown that the presence of basal ganglia hyperintensities produce dysfunction of this structure, and basal ganglia hyperintensities may constitute an epiphenomenon of other (still unknown) pathological mechanisms.

We could not find significant differences on neuropsychological testing between patients with Alzheimer's disease with or without leukoaraiosis. These findings are not surprising, because except for Almkvist et al - who found that patients with Alzheimer's disease with leukoaraiosis had significantly more severe deficits on a test of tactile identification but not on global cognition than patients without leukoaraiosis - most studies could not find a significant association between leukoaraiosis in Alzheimer's disease and deficits on specific cognitive functions. ${ }^{57}$ Alternatively, leukoaraiosis may be related to deficits on more demanding attentional tasks, and this issue should be examined in future studies.

Our finding of thalamic hypoperfusion in Alzheimer's disease with leukoaraiosis is difficult to explain, as only a few patients with Alzheimer's disease and leukoaraiosis had thalamic hyperintensities. Whether the significant thalamic hypoperfusion present in patients with Alzheimer's disease with leukoaraiosis is related to diaschisis produced by thalamic deafferentation due to white matter dysfunction should be further examined.

In conclusion, our study showed significant neurological, psychiatric, and cerebral perfusion correlates of leukoaraiosis in Alzheimer's disease. Future studies should show whether leukoaraiosis produces brain dysfunction by itself or constitutes an epiphenomenon of other pathological processes, and whether leukoaraiosis in focal brain areas is associated with specific psychiatric changes and cognitive deficits.

This study was partially supported by a grant from the Raúl Carrea Institute of Neurological Research, the Fundación Pérez Companc, and the CONICET. We thank Dr Helen Mayberg for helpful suggestions, and Drs Gabriela Kuzis, Laura Jason Silvana Dancygier, and Mariela Juejati, for neuropsychological testing.

1 Hachinski VC, Potter P, Merskey H. Leukoaraiosis. Arch Neurol 1987;44:21-3.

2 Scheltens P, Barkhof F, Leys D, Wolters EC, Ravid R, Kamphorst W. Histopathologic correlates of white matter changes on MRI in Alzheimer's disease and normal aging. Neurology 1995;45:883-8.

3 Scheltens P, Weinstein HC, Leys D. Neuroimaging in the diagnosis of Alzheimer's disease. I. Computer tomography and magnetic resonance imaging. Clin Neurol Neurosurg 1992;94:277-89.

4 Fazekas F, Chawluk JB, Alavi A, Hurtig HI, Zimmerman RA. MR signal abnormalities at $1.5 \mathrm{~T}$ in Alzheimer's RA. MR signal abnormalities at $1.5 \mathrm{~T}$ in Alzheimer's
dementia and normal aging. AfNR Am $\mathcal{F}$ Neuroradiol 1987; dementia
5 Marder K, Richards M, Bello J, Bell K, Sano M, Miller L, et al. Clinical correlates of Alzheimer's disease with and withal. Clinical correlates of Alzheimer's disease with and with-
out silent radiographic abnormalities. Arch Neurol 1995;52: out silent

6 Diaz JF, Merskey H, Hachinski VC, Lee DH, Boniferro M, Wong CJ, et al. Improved recognition of leukoaraiosis and cognitive impairment in Alzheimer's disease. Arch Neurol 1991;48:1022-5.

7 Lopez OL, Becker JT, Rezek D, Wess J, Boller F, Reynolds CF, Panisset M. Neuropsychiatric correlates of cerebral white-matter radiolucencies in probable Alzheimer's disease. Arch Neurol 1992;49:828-34.

8 Almkvist O, Wahlund LO, Andersson G, Basun H, Backman L. White-matter hyperintensity and neuropsyBackman $\mathrm{L}$. White-matter hyperintensity and neuropsy-
chological functions in dementia and healthy aging. Arch Neurol 1992;49:626-32.

9 Fazekas F, Niederkorn K, Schmidt R, Offenbacher H, Horner S, Bertha G, Lechner H. White matter signal abnormalities in normal individuals: correlation with carotid ultrasonography, cerebral blood flow measurements, and cerebrovascular risk factors. Stroke 1988;19: 1285-8.

10 Kawamura J, Meyer JS, Ichijo M, Kobari M, Terayama Y, Weathers S. Correlations of leuko-araiosis with cerebral atrophy and perfusion in elderly normal subjects and demented patients. F Neurol Neurosurg Psychiatry 1993;56: $182-7$.

11 Waldemar G, Christiansen P, Larsson HBW, Hogh P, Laursen $\mathrm{H}$, Lassen NA, Paulson OB. White matter magnetic resonance hyperintensities in dementia of the Alzheimer type: morphological and cerebral blood flow correlates. F Neurol Neurosurg Psychiatry 1994;57:1458-65.

12 Herholz K, Heindel W, Rackl A, Neubauer I, Steinbrich W, Pietrzyk U, et al. Regional cerebral blood flow in patients with leuko-araiosis and atherosclerotic carotid artery disease. Arch Neurol 1990;47:392-6.

13 Sultzer DL, Mahler ME, Cummings JL, Van Gorp WG, Hinkin $\mathrm{CH}$, Brown C. Cortical abnormalities associated with subcortical lesions in vascular dementia: clinical and positron emission tomographic findings. Arch Neurol 1995; 52:773-80.

14 McKhann G, Drachman D, Folstein MF, Katzman R, Price D, Stadlan EM. Clinical diagnosis of Alzheimer's disease: D, Stadlan EM. Clinical diagnosis of Alzheimer's disease:
report of the NINCDS-ADRDA Work Group under the auspices of Department of Health and Human Services Task Force on Alzheimer's Disease. Neurology 1984;34: 939-44.

15 Hachinski VC, Iliff LD, Zilhka L, Du Boulay GH, McAllister VL, Marshall J, et al. Cerebral blood flow in dementia. Arch Neurol 1975;40:97-103.

16 Fahn S, Elton E. UPDRS Development Committee. Unified Parkinson's disease rating scale. In: Fahn S, Marsden CD, Goldstein M, Calne CD, eds. Recent developments in Parkinson's disease. Florham Park, NJ: Macmillan, 1987:153-63.

17 Spitzer RL, Williams JBW, Gibbon M, First MB. The structured clinical interview for DSM-III-R (SCID). I: history, rationale, and description. Arch Gen Psychiatry 1992;49: $624-9$.

18 Hamilton MA. A rating scale for depression. $7 \mathrm{Neurol} \mathrm{Neu-}$ rosurg Psychiatry 1960;23:56-62.

19 Migliorelli R, Teson A, Sabe L, Petracca G, Petracchi M, Leiguarda R, Starkstein SE. Anosognosia in Alzheimer's disease: a study of associated factors. $\mathcal{F}$ Neuropsychiatry Clin Neurosci 1995;7:338-44.

20 Migliorelli R, Petracca G, Teson A, Sabe L, Leiguarda R, Starkstein SE. Neuropsychiatric and neuropsychological correlates of delusions in Alzheimer's disease. Psychol Med 1995;25:505-13.

21 Starkstein SE, Migliorelli R, Teson A, Petracca G, Chemerinski E, Manes F, Leiguarda R. Prevalence and correlates of pathological affective display in Alzheimer's disease. $7 \mathrm{Neu}$ rol Neurosurg Psychiatry 1995;59:55-60.

22 Starkstein SE, Migliorelli R, Manes F, Teson A, Petracca G, Chemerinski E, et al. The prevalence and clinical correlates of apathy and irritability in Alzheimer's disease. European fournal of Neurology 1995;2:540-6.

23 Folstein MF, Folstein SE, McHugh PR. Mini-mental state: a practical method for grading the cognitive state of patients for the clinician. F Psychiatr Res 1975;12:189-98.

24 Raven JC, Court JH, Raven J. Manual for Raven's progressive matrices and vocabulary scales. London: HK Lewis, 1986.

25 Nelson HE. A modified card sorting test sensitive to frontal lobe defects. Cortex 1976;12:313-24.

26 Benton AL. Differential behavioral effects in frontal lobe disease. Neuropsychology 1968;6:53-60.

27 Wechsler D. Wechsler adult intelligence scale manual. New York: Psychological Corporation, 1955.

28 Buschke H, Fuld PA. Evaluating storage, retention, and retrieval in disordered memory and learning. Neurology 1974;24:1019-25.

29 Benton AL. The revised visual retention test. 4 th ed. New York: The Psychological Corporation, 1974.

30 De Renzi E, Faglioni P. Development of a shortened version of the token test. Cortex 1978;14:41-9.

31 Kaplan EF, Goodglass H, Weintraub S. The Boston naming test. Philadelphia: Lea and Febiger, 1983.

32 Matsui T, Hirano A. An atlas for the human brain for computerized tomography. New York: Igaku-Shoin, 1978.

33 Burns A, Philpot MP, Costa DC, EII PJ, Levy R. The invesBurns A, Philpot MP, Costa DC, EII PJ, Levy R. The inves-
tigation of Alzheimer's disease with single photon emission tomography. F Neurol Neurosurg Psychiatry 1989;12:24853. 
34 Starkstein SE, Migliorelli R, Sabe L, Teson A, Vazquez S, Leiguarda R. A SPECT study of anosognosia in AlzheimLeiguarda R. A SPECT study of anosogn
er's disease. Arch Neurol 1995;52:415-20.

35 Scheltens Ph, Barkhof F, Valk J, Algra PR, Van der Hoop RG, Nauta J, Wolters Ch. White matter lesions on magnetic resonance imaging in clinically diagnosed Alzheimer's disease: evidence for heterogeneity. Brain 1992;115: 735-48.

36 Marin RS. Apathy: a neuropsychiatric syndrome. $f \mathrm{Neu}-$ ropsychiatry Clin Neurosci 1991;3:243-54

37 Stuss D, Benson DF. The frontal lobes. New York: Raven Press, 1986.

38 Starkstein SE, Fedoroff JP, Price TR, Leiguarda R, Robinson RG. Apathy following cerebrovascular lesions. Stroke 1993;24;1625-31.
39 Merello M, Sabe L, Teson A, Migliorelli R, Petracchi M, Leiguarda R, Starkstein SE. Extrapyramidalism in Alzheimer's disease: prevalence, psychiatric, and neuropsychological correlates. F Neurol Neurosurg Psychiatry 1994;57: 1103-10.

0 Starkstein SE, Vazquez S, Merello M, Teson A, Petracchi M, Leiguarda R. A SPECT study of parkinsonism in Alzheimer's disease. I Neuropsychiatry Clin Neurosci 1995;7:308-13. 41 Brooks DJ. Functional imaging in relation to parkinsonian syndrome. F Neurol Sci 1993;115:1-17.

42 Otsuka M, Ichiya Y, Hosokawa S, Kuwabara Y, Tahara T, Fukumura T. Striatal blood flow, glucose metabolism and ${ }^{18} \mathrm{~F}$-dopa uptake: difference in Parkinson's disease and atypical parkinsonism. F Neurol Neurosurg Psychiatry 1991; 54:898-904. 